$\begin{array}{lllllllll}\text { Volume 12, Nomor 1, } & \text { Mei 2020, pp } & 73-83 & \text { Copyright } & \text { C } & 2017\end{array}$

Jurnal Akuntansi, Program Studi Akuntansi, Fakultas Ekonomi,

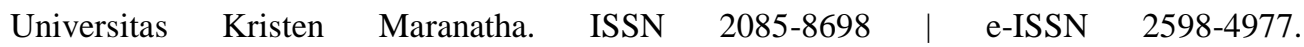

http://journal.maranatha.edu

\title{
Perbandingan Kinerja Portofolio yang Dibentuk dengan Single Index Model pada Saham-Saham yang Terdaftar dalam Indeks LQ45 dan Kompas 100 Tahun 2018
}

\author{
Dini Iskandar \\ Fakultas Ekonomi Program Studi Manajemen-Univ. Kristen Maranatha \\ (Jl. Prof. Drg. Suria Sumantri No. 65, Bandung) \\ dini_djman@yahoo.com \\ Martalena \\ Fakultas Ekonomi Program Studi Manajemen-Univ. Kristen Maranatha \\ (Jl. Prof. Drg. Suria Sumantri No. 65, Bandung) \\ lena.sgurky@gmail.com \\ Natasha Desiree Julianto \\ Fakultas Ekonomi Program Studi Manajemen-Univ. Kristen Maranatha \\ (Jl. Prof. Drg. Suria Sumantri No. 65, Bandung)
}

\begin{abstract}
Stocks as an investment instrument that categorized as a high risk and high return instrument. Therefore, investors should distributed their invesment funds in a number of shares by forming an optimal portfolio where the highest return is obtain at a certain risk or the lowest risk at certain return. On this study the portfolio forming used the Single Index Model. Portfolio formed from stocks at LQ 45 Index and Kompas 100 Index by aim to get the comparison of their performance.The result of this study indicate that $L Q 45$ portfolio that containing PTBA, ICBP, BBCA, PGAS and ANTM has a lower return than Kompas 100 portfolio that containing KREN,CPIN, PTBA and JFPA. The performance of both portfolio that analyze by Sharpe Index, Treynor Index and Jensen Index indicate that portfolio of Kompas 100 better than portfolio of $L Q 45$, however both of them showed the good performance because their result are positif that mean better than market.
\end{abstract}

Keywords: Portfolio, Single Index Model, Sharpe Index, Treynor Index, and Jensen Index 


\begin{abstract}
Abstrak
Saham merupakan investasi yang berisiko tinggi selain juga berpotensi memberikan tingkat pengembalian yang tinggi. Oleh sebab itu investor sebaiknya mendistribusikan dana investasinya pada beberapa saham dengan membentuk portofolio yang optimal, dimana akan diperoleh hasil return tertinggi pada tingkat risiko tertentu atau risiko terendah pada tingkat pengembalian tertentu. Pada penelitian ini pembentukan portofolio dilakukan dengan Model Indeks Tunggal. Portofolio dibentuk pada Indeks LQ 45 dan Kompas 100 dengan tujuan untuk mendapatkan perbandingan. Berdasarkan hasil penelitian yang dilakukan memperlihatkan bahwa Portofolio yang dibentuk dari LQ 45 yang berisikan 5 saham yaitu PTBA, ICBP, BBCA, PGAS dan ANTM memperlihatkan return portofolio yang lebih rendah dibandingkan return portofolio yang dibentuk dari Kompas 100 yang terdiri dari 4 saham yaitu KREN, CPIN, PTBA dan JFPA. Kinerja kedua portofolio yang dianalisis dengan Indeks Sharpe, Indeks Treynor dan Indeks Jensen memperlihatkan bahwa kinerja portofolio yang dibentuk dari Kompas 100 lebih baik dibandingkan Portofolio yang dibentuk dari LQ 45 meskipun kinerja kedua portofolio tersebut baik karena memberikan hasil positif yang berarti kinerjanya berada diatas pasar.
\end{abstract}

\title{
Kata Kunci: Portofolio, Model Indeks Tunggal, Indeks Sharpe, Indeks Treynor, dan Indeks Jensen
}

\section{Pendahuluan}

Investasi merupakan salah satu cara agar seseorang bisa memperoleh pendapatan yang lebih baik daripada saat ini. Investasi secara umum akan memberikan hasil yang lebih baik jika dapat dilakukan dalam rentang waktu yang semakin panjang.

Dalam investasi saham investor perlu untuk selalu mempertimbangkan keseimbangan antara tingkat pengembalian (return) dan risiko agar investasi dapat mencapai tujuan yang telah ditetapkan. Hal ini perlu dilakukan karena investasi dalam saham merupakan investasi yang tingkat risikonya cukup tinggi meskipun juga menjanjikan hasil yang cukup tinggi juga sesuai dengan konsep high risk high return. Oleh sebab itu investor perlu memahami terlebih dahulu karakteristik investasi saham agar dapat mencapai tujuan investasinya. Risiko didefinisikan sebagai perbedaan antara hasil yang diharapkan (expected return) dan realisasinya (Zubir 2011, 19). Harry Markowitz mengatakan bahwa keputusan investasi yang dibuat oleh investor didasarkan pada expected return dan varian dari return (sebagai ukuran risiko) (Markowitz dalam Zubir 2011,19).

Salah satu cara yang dapat digunakan untuk mengelola risiko dalam investasi saham adalah melakukan diversifikasi dengan membentuk portofolio yang terdiri dari beberapa saham yang akan memberikan return dan risiko yang optimal. Investor dapat membentuk portofolio yang akan memberikan return maksimal pada tingkat risiko tertentu atau return tertentu pada tingkat risiko minimal.

Dalam perkembangan berikutnya dikembangkan model lain yang disebut Single Index Model. Model ini dikembangkan karena dalam perhitungan dengan model Markowitz semakin banyak sekuritas yang dimasukkan ke dalam portofolio maka akan semakin banyak perhitungan kovarians dan koefisien korelasi yang harus dihitung, sehingga perhitungannya tidak sederhana. Model Indeks Tunggal didasarkan pada pengamatan bahwa harga dari suatu sekuritas berfluktuasi searah dengan indeks harga pasar (Jogiyanto, 2012). 
Penelitian ini akan menggunakan model Indeks Tunggal untuk membentuk portofolio optimal pada indeks LQ45 yang merupakan kumpulan dari saham-saham yang memiliki likuiditas dan kapitalisasi terbesar dan membandingkan kinerjanya dengan portofolio yang dibentuk dari indeks Kompas 100. Penilaian kinerja sendiri akan dilakukan dengan menggunakan Indeks Sharpe, Indeks Treynor, dan Indeks Jensen

\section{Kerangka Teoritis}

\section{Investasi}

Investasi memiliki beberapa pengertian yang sedikit berbeda satu dengan yang lainnya. Menurut Tandelilin, investasi adalah komitmen atas sejumlah dana atau sumber daya lainnya yang dilakukan pada saat ini, dengan tujuan memperoleh sejumlah keuntungan dimasa yang akan datang (Tandelilin, 2010). Sementara menurut Hartono (2012), investasi merupakan penundaan konsumsi sekarang untuk dimasukkan ke aktiva produktif selama periode waktu yang tertentu. Agar dapat memperoleh nilai yang lebih tinggi maka dana investasi harus ditempatkan pada aktiva atau instrumen yang produktif. Tingkat keuntungan atau hasil yang diperoleh dari investasi sering disebut return. Return terbagi menjadi dua yaitu return realisasian (realized return) dan return yang diharapkan (expected return). Return realisasian merupakan return yang telah terjadi, sementara return yang diharapkan merupakan return yang diharapkan investor akan diperoleh di masa yang akan datang.

Karena adanya rentang waktu antara waktu pengorbanan sejumlah dana tersebut dan waktu diterimanya hasil dari investasi tersebut, maka terdapat risiko atas investasi tersebut.Risiko diartikan sebagai perbedaan antara hasil yang diharapkan (expected return) dan realisasinya (Zubir, 2011). Sementara Husnan (2009) menyatakan risiko dapat diartikan sebagai kemungkinan tingkat keuntungan yang diperoleh menyimpang dari tingkat keuntungan yang diharapkan.

\section{Saham Biasa}

Saham biasa merupakan surat berharga yang menyatakan kepemilikan atas sebuah perusahaan. Menurut Tandelilin saham biasa adalah sertifikat yang menunjukkan bukti kepemilikan suatu perusahaan (Tandelilin, 2010). Menurut Hartono (2012) jika perusahaan hanya mengeluarkan satu jenis saham maka itu biasanya adalah saham biasa. Pemilik saham adalah pemilik perusahaan yang mewakilkan kepada manajemen untuk menjalankan operasi perusahaan.

Saham merupakan salah satu instrumen investasi yang diperdagangkan di Pasar Modal. Di Indonesia pasar modalnya dikenal dengan nama Bursa Efek Indonesia (BEI) yang berpusat di Jakarta.

Dalam perdagangan saham terdapat beberapa pengelompokan saham di BEI diantaranya adalah indeks harga saham gabungan (IHSG), Indeks LQ45 dan Kompas 100. Dalam buku Panduan Indeks Harga Saham Bursa Efek Indonesia (2010), IHSG menggunakan semua emiten yang tercatat sebagai komponen perhitungan indeks. Indeks LQ45 menggunakan 45 emiten yang dipilih berdasarkan pertimbangan likuiditas dan kapitalisasi pasar dengan kriteria tertentu. Indeks Kompas 100 menggunakan 100 emiten yang dipilih berdasarkan likuiditas dan kapitalisasi pasar, dengan kriteria-kriteria yang telah ditentukan.

Return dalam investasi saham dapat diperoleh dari 2 sumber yaitu Capital Gain dan Dividen. Capital Gain merupakan selisih positif antara harga jual bersih saham dengan harga beli bersih saham. Sementara dividen merupakan laba yang dibagikan kepada pemegang saham (Tandelilin, 2010). Besar kecilnya dividen yang dibagikan ditentukan berdasarkan 
Rapat Umum Pemegang Saham (RUPS) perusahaan.

Return saham dapat dihitung dengan beberapa cara antara lain return total yang menggabungkan Capital Gain/Loss dengan dividen dan return yang hanya berasal dari capital gain.

Return Total $=$ Capital Gain $($ Loss $)+$ Yield

Capital Gain $=\frac{\mathrm{P}_{\mathrm{t}}-\mathrm{P}_{\mathrm{t}-1}}{\mathrm{P}_{\mathrm{t}-1}}$

Return saham $=\frac{\mathrm{P}_{\mathrm{t}}-\mathrm{P}_{\mathrm{t}-1}+\mathrm{D}_{1}}{\mathrm{P}_{\mathrm{t}-1}}$

Karena $D_{1}$ atau dividen biasanya hanya dibagikan satu kali dalam setahun sementara data yang digunakan adalah data bulanan maka dalam penelitian ini return hanya akan menggunakan Capital Gain.

Return ekspektasian dapat dihitung dengan metode rata-rata. Menurut Hartono (2012) metode rata-rata mengasumsikan bahwa return ekpektasian dapat dianggap sama dengan rata-rata historisnya.

Investasi dalam saham merupakan investasi yang memiliki risiko sehingga tingkat risiko ini juga harus diperhitungkan. Risiko dapat dihitung dengan menggunakan data historis. Umumnya risiko ini diukur dengan ukuran penyimpangan yaitu Standar Deviasi.

$\mathrm{SD}=\sqrt{\frac{\sum_{\mathrm{i}=1}^{\mathrm{n}}\left(\mathrm{X}_{\mathrm{i}}-\mathrm{E}\left(\mathrm{X}_{\mathrm{i}}\right)\right)^{2}}{\mathrm{n}-1}}$

Investor saham sebaiknya melakukan diversifikasi dalam beberapa saham agar dapat memperoleh hasil investasi yang optimal berupa portofolio yang akan memberikan tingkat risiko tertentu dengan return tertinggi atau return tertentu dengan risiko terendah.

\section{Portofolio}

Pengertian umum dari portofolio investasi merupakan kumpulan dari sejumlah instrumen investasi. Tujuan pembentukan portofolio investasi adalah untuk meminimalkan tingkat risiko yang dihadapi oleh investor. Dalam menyusun portofolio pada kondisi dimana short selling tidak diperkenankan maka $X_{A}+X_{B}=1$ dan $X_{A}$, $X_{B} \geq 0$ (Husnan, 2009).

Menurut Tandelilin (2010), prinsip diversifikasi ada dua yaitu diversifikasi random dan diversifikasi Markowitz.

1. Diversifikasi Random

Investasi secara acak pada berbagai jenis aset dalam suatu portofolio tanpa memperhatikan karakteristik dan hubungan antar-aset.

2. Diversifikasi Markowtiz

Pembentukan portofolio dengan mempertimbangkan kovarian dan koefisien korelasi negatif antar-aset agar dapat menurunkan risiko portofolio. Koefisien korelasi merupakan ukuran statistik yang menunjukkan pergerakan relatif antar dua variabel dengan kisar besaran koefisien minimum -1 hingga maksimum +1 . Kovarians merupakan ukuran absolut yang menunjukkan dua variabel bergerak secara bersama-sama.

Return harapan atau ekspektasian dari portofolio dapat dihitung dengan rumus :

$E\left(R_{p}\right)=\sum_{i=1}^{n} W_{i} \cdot E\left(R_{i}\right)$

dimana :

$\mathrm{E}\left(\mathrm{R}_{\mathrm{p}}\right)=$ return harapan dari portofolio

$\mathrm{Wi}=$ bobot portofolio sekuritas ke-i

$\Sigma \mathrm{Wi}=$ jumlah total bobot portofolio $=1,0$

$\mathrm{E}\left(\mathrm{R}_{\mathrm{i}}\right) \quad=$ return harapan dari sekuritas ke-i

$\mathrm{n} \quad=$ jumlah sekuritas-sekuritas yang ada dalam portofolio

Risiko portofolio yang terdiri dari 2 saham dapat dihitung sebagai berikut :

$\sigma_{\mathrm{p}}=\mathrm{W}_{\mathrm{A}}^{2} \cdot \sigma_{\mathrm{A}}^{2}+\mathrm{W}_{\mathrm{B}}^{2} \cdot \sigma_{\mathrm{B}}^{2}+2 \cdot\left[\mathrm{W}_{\mathrm{A}}\right]\left[\mathrm{W}_{\mathrm{B}}\right]\left[\rho_{\mathrm{AB}}\right]\left[\sigma_{\mathrm{A}} \cdot \sigma_{\mathrm{B}}\right]^{\frac{1}{2}}$

dimana :

$\sigma_{\mathrm{p}} \quad=$ deviasi standar portofolio

$\mathrm{W}_{\mathrm{A}, \mathrm{B}}=$ bobot portofolio pada aset $\mathrm{A}$ dan B

$\rho_{\mathrm{A}, \mathrm{B}} \quad=$ koefisien korelasi aset $\mathrm{A}$ dan $\mathrm{B}$ 
Jika jumlah saham yang dimasukkan ke dalam portofolio semakin bertambah katakanlah sejumlah $\mathrm{n}$ maka rumus untuk menghitung standar deviasi portofolio akan menjadi :

$\sigma_{p}^{2}=\sum_{i=1}^{n} W_{i}^{2} \sigma_{i}^{2}+\sum_{i=1}^{n} \sum_{i=1}^{n} W_{i} W_{j} \rho_{i j}$

dimana :

$\sigma_{\mathrm{p}}^{2} \quad=$ varians return portofolio

$\sigma^{2}{ }_{i}^{2} \quad=$ varians return sekuritas $\mathrm{i}$

$\rho_{\mathrm{ij}} \quad=$ kovarians antara return sekuritas $\mathrm{i}$ dan $\mathrm{j}$

$\mathrm{W}_{\mathrm{i}} \quad$ =bobot dana yang diinvestasikan pada sekuritas i

Dengan menggunakan rumus diatas maka semakin banyak saham yang dimasukkan ke dalam portofolio maka akan semakin panjang rumus tersebut karena jika ada 5 saham maka akan ada 5 pasang $\mathrm{W}_{\mathrm{i}}^{2} \sigma_{\mathrm{i}}^{2}$ dan akan ada 10 pasang korelasi.

Penyederhanaan atas perhitungan model Markowitz tersebut dilakukan oleh William Sharpe yang disebut dengan model indeks tunggal (Single Index Model).

\section{Model Indeks Tunggal (Single Index Model)}

Bila dilakukan pengamatan secara umum jika pasar membaik maka harga sahamsaham individual biasanya mengalami kenaikan juga, demikian juga sebaliknya. Hal ini memperlihatkan bahwa tingkat keuntungan suatu saham berkorelasi dengan tingkat keuntungan pasar. Atas dasar ini return suatu saham dapat dihitung sebagai berikut (Husnan, 2009) :

$\mathrm{R}_{\mathrm{i}}=\mathrm{a}_{\mathrm{i}}+\beta_{\mathrm{i}} \mathrm{R}_{\mathrm{m}}$

dimana :

$\mathrm{a}_{\mathrm{i}} \quad=$ bagian dari tingkat keuntungan saham i yang tidak dipengaruhi oleh perubahan pasar dan merupakan variabel acak

$\mathrm{R}_{\mathrm{m}} \quad=$ tingkat keuntungan indeks pasar dan merupakan variabel acak $\beta \mathrm{i} \quad=$ beta yaitu parameter yang mengukur perubahan yang diharapkan pada $R_{i}$ kalau terjadi perubahan pada $R_{m}$

Parameter $a_{i}$ dapat dipecah menjadi 2 bagian yaitu :

$\mathrm{a}_{\mathrm{i}}=\alpha_{\mathrm{i}}+\mathrm{e}_{\mathrm{i}}$

dan ei mempunyai nilai pengharapan $=0$. Sehingga persamaan diatas dapat dituliskan menjadi :

$\mathrm{R}_{\mathrm{i}}=\mathrm{a}_{\mathrm{i}}+\beta_{\mathrm{i}} \mathrm{R}_{\mathrm{m}}+\mathrm{e}_{\mathrm{i}}$

Asumsi :

1. Indeks tidak berkorelasi dengan unique return:

$\mathrm{E}\left[\mathrm{e}_{\mathrm{i}}\left(\mathrm{R}_{\mathrm{m}}-\mathrm{E}\left(\mathrm{R}_{\mathrm{m}}\right)\right)\right]=0$

untuk setiap saham $\mathrm{i}=1$.....

2. Sekuritas hanya dipengaruhi oleh pasar

$\mathrm{E}\left(\mathrm{e}_{\mathrm{i}} \mathrm{e}_{\mathrm{j}}\right)=0$

untuk setiap pasang saham $\mathrm{i}=1$...N dan $\mathrm{j}=1$... $\mathrm{N}$ tetapi $\mathrm{i} \neq \mathrm{j}$

Jadi, penggunaan model indeks tunggal menghasilkan tingkat keuntungan yang diharapkan, deviasi standar dan covariance antar saham sebagai berikut :

1. Tingkat keuntungan yang diharapkan

$$
\mathrm{E}\left(\mathrm{R}_{\mathrm{i}}\right)=\alpha_{\mathrm{i}}+\beta_{\mathrm{i}} \mathrm{R}_{\mathrm{m}}
$$

2. Variance tingkat keuntungan

$$
\sigma_{\mathrm{i}}^{2}=\beta_{\mathrm{i}}^{2} \cdot \sigma_{\mathrm{m}}^{2}+\sigma_{\mathrm{ei}}^{2}
$$

3. Covariance tingkat keuntungan sekuritas $\mathrm{i}$ dan $\mathrm{j}$

$\sigma_{\mathrm{ij}}=\beta_{\mathrm{i}} \beta_{\mathrm{j}} \sigma_{\mathrm{m}}^{2}$

$\beta$ dapat dihitung sebagai berikut :

$\beta_{\mathrm{i}}=\frac{\sigma_{\mathrm{jM}}}{\sigma^{2}{ }_{\mathrm{M}}}$ atau dapat diuraikan menjadi :

$\beta_{\mathrm{i}}=\frac{\sum_{\mathrm{i}=1}^{\mathrm{n}}\left(\mathrm{R}_{\mathrm{it}}-\overline{\mathrm{R}}_{\mathrm{it}}\right)\left(\mathrm{R}_{\mathrm{Mt}}-\overline{\mathrm{R}}_{\mathrm{Mt}}\right)}{\sum_{\mathrm{i}=1}^{\mathrm{n}}\left(\mathrm{R}_{\mathrm{Mt}}-\overline{\mathrm{R}}_{\mathrm{Mt}}\right)^{2}}$ 
Model indeks tunggal juga dapat langsung digunakan untuk analisis portofolio sebagai berikut :

1. Return ekspektasian portofolio

$$
E\left(R_{p}\right)=\sum_{i=1}^{n} W_{i} \cdot \alpha_{i}+\sum_{i=1}^{n} W_{i} \cdot \beta_{i} \cdot E\left(R_{M}\right)
$$

Beberapa karakteristik model indeks tunggal :

- Beta dari portofolio $\left(\beta_{\mathrm{p}}\right)$ merupakan rata-rata tertimbang dari Beta masing-masing sekuritas $\left(\beta_{\mathrm{i}}\right)$ :

$$
\beta_{\mathrm{p}}=\sum_{\mathrm{i}=1}^{\mathrm{n}} \mathrm{W}_{\mathrm{i}} \cdot \beta_{\mathrm{i}}
$$

- Alpha dari portofolio $\left(\alpha_{\mathrm{p}}\right)$ juga merupakan rata-rata tertimbang dari Alpha tiap-tiap sekuritas $\left(\alpha_{\mathrm{i}}\right)$ :

$$
\alpha_{p}=\sum_{i=1}^{n} W_{i} \cdot \alpha_{i}
$$

Dengan mensubstitusikan kedua karakteristik ini ke persamaan diatas maka return ekspektasian portofolio menjadi :

$E\left(R_{p}\right)=\alpha_{p}+\beta_{p} \cdot E\left(R_{M}\right)$

2. Risiko portofolio

Dengan menggunakan karakteristik model indeks tunggal maka varians dari portofolio dapat dituliskan sebagai berikut :

$$
\sigma_{\mathrm{p}}{ }^{2}=\beta_{\mathrm{p}}^{2} \cdot \sigma_{\mathrm{M}}^{2}+\left(\sum_{\mathrm{i}=1}^{\mathrm{n}} \mathrm{W}_{\mathrm{i}} \cdot \sigma_{\mathrm{ei}}\right)^{2}
$$

Langkah pertama dalam membentuk portofolio menggunakan model indeks tunggal adalah dengan menghitung Excess Return to Beta (ERB). ERB merupakan rasio antara excess return dengan Beta.

$\mathrm{ERB}_{\mathrm{i}}=\frac{\mathrm{E}\left(\mathrm{R}_{\mathrm{i}}\right)-\mathrm{R}_{\mathrm{BR}}}{\beta_{\mathrm{i}}}$ dimana :

$\mathrm{ERB}_{\mathrm{i}}=$ excess return to beta sekuritas

$\mathrm{E}\left(\mathrm{R}_{\mathrm{i}}\right) \quad \begin{aligned} & \mathrm{ke}-\mathrm{i} \\ & =\text { return ekspektasian untuk }\end{aligned}$ sekuritas ke-i

$\mathrm{R}_{\mathrm{BR}} \quad=$ return untuk aktiva bebas risiko

$\beta_{\mathrm{i}} \quad=$ beta sekuritas ke- $\mathrm{i}$

Portofolio yang optimal akan berisikan saham-saham yang memiliki ERB yang tinggi. Untuk menentukan pembatas (cut-off point) saham-saham mana yang dianggap memiliki ERB yang tinggi maka dilakukan langkah-langkah berikut :

1. Sekuritas diurutkan berdasarkan ERB terrtinggi ke ERB terendah

2. Hitung nilai Ai dan Bi untuk masingmasing sekuritas ke-i sebagai berikut :

$$
\begin{aligned}
& \mathrm{A}_{\mathrm{i}}=\frac{\left[\mathrm{E}\left(\mathrm{R}_{\mathrm{i}}\right)-\mathrm{R}_{\mathrm{BR}}\right] \cdot \beta_{\mathrm{i}}}{\sigma_{\mathrm{ei}}{ }^{2}} \\
& \mathrm{~B}_{\mathrm{i}}=\frac{\beta_{\mathrm{i}}{ }^{2}}{{\sigma_{\mathrm{ei}}}^{2}}
\end{aligned}
$$

3. Hitung nilai $\mathrm{C}_{\mathrm{i}}$

$$
\mathrm{C}_{\mathrm{i}}=\frac{\sigma_{\mathrm{M}}^{2} \cdot \sum_{\mathrm{i}=1}^{\mathrm{i}} \mathrm{A}_{\mathrm{j}}}{1+\sigma_{\mathrm{M}}^{2} \cdot \sum_{\mathrm{j}=1}^{\mathrm{i}} \mathrm{B}_{\mathrm{j}}}
$$

Dengan mensubstitusikan nilai $\mathrm{A}_{\mathrm{i}}$ dan $\mathrm{B}_{\mathrm{i}}$ pada poin 2 diatas maka nilai $\mathrm{C}_{\mathrm{i}}$ dapat menjadi :

$$
C_{i}=\frac{\sigma_{M}{ }^{2} \cdot \sum_{j=1}^{i} \frac{\left[E\left(R_{j}\right)-R_{B R}\right] \cdot \beta_{j}}{\sigma_{e j}^{2}}}{1+\sigma_{M}^{2} \cdot \sum_{j=1}^{i} \frac{\beta_{j}^{2}}{\sigma_{e j}{ }^{2}}}
$$

- Besarnya cut-off point (C*) merupakan nilai $\mathrm{Ci}$ dimana $\mathrm{ERB}$ terakhir kali lebih besar dari nilai Ci.

- Saham-saham yang masuk kedalam portofolio adalah saham-saham yang memiliki nilai ERB lebih besar atau sama dengan ERB pada titik $C^{*}$.

4. Setelah diketahui saham-saham mana yang masuk kedalam portofolio maka langkah berikutnya adalah menentukan komposisi masing - masing dalam 
portofolio. Besarnya proporsi masingmasing dihitung sebagai berikut :

$$
\mathrm{W}_{\mathrm{i}}=\frac{\mathrm{Z}_{\mathrm{i}}}{\sum_{\mathrm{j}=1}^{\mathrm{k}} \mathrm{Z}_{\mathrm{j}}}
$$

Nilai $Z_{\mathrm{i}}$ dapat dihitung sebagai berikut :

$$
Z_{i}=\frac{\beta_{i}}{\sigma_{e i}{ }^{2}} \cdot\left(E R B_{i}-C^{*}\right)
$$

\section{Evaluasi Kinerja Portofolio}

Setelah sebuah portofolio terbentuk, seiring berjalannya waktu maka portofolio tersebut perlu dievaluasi kinerjanya. Menurut Tandelilin (2010) ada beberapa faktor yang perlu diperhatikan:

- Tingkat risiko

- Periode waktu

- Penggunaan patok duga (benchmark) yang sesuai

- Tujuan investasi

Salah satu metode yang dapat digunakan untuk mengukur kinerja portofolio adalah Risk Adjusted Performance (Tandelilin, 2010). Beberapa ukuran kinerja yang sudah memasukkan risiko adalah Indeks Sharpe, Indeks Treynor dan Indeks Jensen.

Indeks Sharpe menggunakan patok duga capital market line. Rumus Indeks Sharpe adalah :

$\widehat{\mathrm{S}}_{\mathrm{p}}=\frac{\overline{\mathrm{R}}_{\mathrm{p}}-\overline{\mathrm{RF}}}{\sigma_{\mathrm{TR}}}$

Indeks Treynor menggunakan patok duga security market line. Rumus Indeks Treynor adalah :

$\widehat{\mathrm{T}}_{\mathrm{p}}=\frac{\overline{\mathrm{R}}_{\mathrm{p}}-\overline{\mathrm{RF}}}{\widehat{\beta}_{\mathrm{p}}}$

Indeks Jensen merupakan pengukuran yang memperlihatkan perbedaan antara return aktual dengan return ekspektasian, dapat dihitung dengan rumus berikut:

$\hat{\mathrm{J}}_{\mathrm{p}}=\overline{\mathrm{R}}_{\mathrm{p}}-\left[\overline{\mathrm{RF}}+\left(\mathrm{R}_{\mathrm{M}}-\overline{\mathrm{RF}}\right) \cdot \hat{\beta}_{\mathrm{p}}\right]$

\section{Metode Penelitian}

\section{Jenis Penelitian}

Berdasarkan tujuan penelitian, maka jenis penelitian ini adalah riset deskriptif. Menurut Suliyanto (2009:9), riset deskriptif adalah riset yang dilakukan untuk menganalisis satu atau lebih variabel tanpa membuat perbandingan atau menghubungkan antara variabel yang satu dengan variabel yang lain.

\section{Populasi dan Sampel}

Populasi pada penelitian ini adalah indeksindeks yang ada di Bursa Efek Indonesia dengan sampel adalah Indeks LQ 45 dan Indeks Kompas 100. Sampel yang digunakan pada penelitian ini diambil dengan menggunakan teknik non probability sampling dengan metode purposive sampling. Non probability sampling adalah pengambilan sampel yang tidak memberikan peluang atau kesempatan yang sama bagi setiap unsur atau anggota populasi untuk dipilih menjadi sampel. Sedangkan purposive sampling adalah teknik penentuan sampel dengan pertimbangan atau kriteria tertentu (Sugiyono, 2010:84-85). Kriteria yang digunakan dalam pemilihan sampel pada penelitian ini adalah indeks saham LQ45 dan Kompas 100 yang konsisten berada pada tahun 2018.

\section{Teknik Pengumpulan Data}

Teknik pengumpulan data yang digunakan pada penelitian ini adalah dokumentasi. Jenis data yang digunakan adalah data sekunder, yaitu data yang diterbitkan atau digunakan oleh organisasi yang bukan pengelolanya (Suliyanto, 2009:132). Data sekunder yang digunakan pada penelitian ini adalah data penutupan IHSG dan BI Rate. Sumber data diperoleh dengan mengakses website www.idx.co.id. 


\section{Hasil Penelitian dan Pembahasan}

\section{Hasil Penelitian}

Dalam melakukan pengolahan data untuk membentuk portofolio pada kedua kelompok indeks baik yang LQ45 maupun Kompas 100, peneliti tidak menggunakan semua data yang menghasilkan beta negatif walaupun Excess Return Over Beta yang dihasilkan berada dalam urutan yang tinggi karena dengan beta yang negatif akan menghasilkan komposisi yang negatif yang berarti saham tersebut dilakukan short selling atau dengan kata lain akan melanggar ketentuan dasar yaitu $\mathrm{X}_{\mathrm{A}}+\mathrm{X}_{\mathrm{B}}=$ 1 dan $X_{\mathrm{A}}, \mathrm{X}_{\mathrm{B}} \geq 0$.

\section{Portofolio LQ45}

Saham-saham yang masuk dalam portofolio LQ45 adalah PTBA, ICBP, BBCA, PGAS dan ANTM. Komposisi masing-masing saham dalam portofolio adalah seperti yang terlihat dalam tabel berikut ini yaitu kolom Wi :

\section{Tabel 1}

Komposisi Saham Portofolio LQ45

\begin{tabular}{|c|c|c|c|c|}
\hline Saham & $\mathrm{Zi}$ & $\mathrm{Wi}$ & $\mathrm{E}(\mathrm{Ri})$ & $\mathrm{E}(\mathrm{Rp})$ \\
\hline PTBA & 28,1655 & 0,2957 & 0,6600 & 0,1952 \\
\hline ICBP & 41,0022 & 0,4305 & 0,1728 & 0,0744 \\
\hline BBCA & 23,8697 & 0,2506 & 0,1865 & 0,0467 \\
\hline PGAS & 1,3433 & 0,0141 & 0,3595 & 0,0051 \\
\hline ANTM & 0,8597 & 0,0090 & 0,3653 & 0,0033 \\
\hline$\Sigma$ & 95,2403 & 1,0000 & & 0,3247 \\
\hline \multicolumn{5}{|l|}{} \\
\hline Saham & $\beta \mathrm{i}$ & $\mathrm{Bp}$ & $\sigma^{2} \mathrm{ei}$ & $\left(\mathrm{Wi}^{2} \cdot \sigma^{2} \mathrm{ei}\right)$ \\
\hline PTBA & 1,5899 & 0,4702 & 0,0163 & 0,001426 \\
\hline ICBP & 0,6396 & 0,2754 & 0,0015 & 0,000278 \\
\hline BBCA & 1,1340 & 0,2842 & 0,0012 & 0,000075 \\
\hline PGAS & 2,9230 & 0,0412 & 0,0245 & 0,000005 \\
\hline ANTM & 3,1402 & 0,0283 & 0,0214 & 0,000002 \\
\hline$\Sigma$ & & 1,0993 & & 0,001786 \\
\hline
\end{tabular}

Berdasarkan tabel di atas maka return portofolio $\mathrm{E}(\mathrm{Rp})$ yang diperoleh adalah sebesar 0,3247 atau $32,47 \%$ yang berarti berada di atas return ICBP dan BBCA. Sementara $\beta p$ yang merupakan ukuran risiko sistematik sebesar 1,0993 yang berarti berada di bawah $\beta$ dari PTBA, BBCA, PGAS dan ANTM. Jika risiko total 80 yang diukur dengan $\sigma \mathrm{p}^{2}$ dihitung dengan rumus :

$$
\sigma_{\mathrm{p}}{ }^{2}=\beta_{\mathrm{p}}^{2} \cdot \sigma_{\mathrm{M}}{ }^{2}+\left(\sum_{\mathrm{i}=1}^{\mathrm{n}} \mathrm{W}_{\mathrm{i}} \cdot \sigma_{\mathrm{ei}}\right)^{2}
$$

maka hasilnya adalah 0,0029 yang berarti op adalah 0,0539 .

\section{Portofolio Kompas 100}

Saham-saham yang masuk dalam portofolio Kompas 100 adalah saham KREN, CPIN, PTBA dan JFPA. Komposisi masingmasing dalam portofolio adalah :

\section{Tabel 2}

\section{Komposisi Portofolio Saham Kompas} 100

\begin{tabular}{|c|c|c|c|c|}
\hline Saham & $\mathrm{Zi}$ & $\mathrm{Xi}$ & $\mathrm{E}(\mathrm{Ri})$ & $\mathrm{E}(\mathrm{Rp})$ \\
\hline KREN & 34,5451 & 0,1801 & 0,2454 & 0,0442 \\
\hline CPIN & 133,3359 & 0,6952 & 0,9456 & 0,6574 \\
\hline PTBA & 14,0459 & 0,0732 & 0,6600 & 0,0483 \\
\hline JFPA & 9,8725 & 0,0515 & 0,5728 & 0,0295 \\
\hline$\Sigma$ & 191,7994 & 1,0000 & & 0,7794 \\
\hline \multicolumn{5}{|l|}{} \\
\hline Saham & $\beta \mathrm{i}$ & $\mathrm{Bp}$ & $\sigma^{2} \mathrm{ei}$ & $\left(\mathrm{Wi}^{2} \cdot \sigma^{2} \mathrm{ei}\right)$ \\
\hline KREN & 0,0327 & 0,0059 & 0,0054 & 0,000175 \\
\hline CPIN & 1,6786 & 1,1669 & 0,0037 & 0,001788 \\
\hline PTBA & 1,5899 & 0,1164 & 0,0163 & 0,000087 \\
\hline JFPA & 1,8440 & 0,0949 & 0,0082 & 0,000022 \\
\hline$\Sigma$ & & 1,3842 & & 0,002072 \\
\hline
\end{tabular}

Berdasarkan data dalam tabel di atas maka dapat dilihat return portofolio yang dihasilkan atau $\mathrm{E}(\mathrm{Rp})$ adalah 0,7794 atau $77,94 \%$ yang berarti berada di atas return KREN, PTBA dan JFPA. Risiko sistematik yang diukur dengan $\beta$ hasilnya $\beta p$ sebesar 1,3842 yang berarti di bawah $\beta$ dari CPIN, PTBA dan JFPA. Sementara untuk $\sigma p^{2}$ sebesar 0,0038 yang berarti $\sigma p$ adalah 0,0616 .

\section{Evaluasi Kinerja Portofolio}

Untuk dapat menilai apakah portofolio yang terbentuk memiliki kinerja yang baik atau memiliki kinerja diatas rata-rata pasar maka perlu dilakukan evaluasi terhadap kinerja portofolio tersebut. Dalam penelitian ini evaluasi kinerja portofolio akan dilakukan 
dengan menggunakan Indeks Sharpe, Indeks Treynor dan Indeks Jensen.

1. Indeks Sharpe

Indeks Sharpe menggunakan patok duga Capital Market Line dan semakin tinggi nilainya akan semakin baik kinerja portofolio tersebut. Perhitungan indeks Sharpe untuk kedua portofolio tersebut adalah sebagai berikut :

$\mathrm{S}_{\mathrm{p}}(\mathrm{LQ} 45)=\frac{0,3247-0,0510}{0,0539}=5,0779$

$\mathrm{S}_{\mathrm{p}}\left(\right.$ Kompas 100) $=\frac{0,7794-0,0510}{0,0616}=11,8247$

2. Indeks Treynor

Indeks Treynor menggunakan patok duga Security Market Line dan semakin tinggi nilainya akan semakin baik kinerja portofolio tersebut. Perhitungan indeks Treynor untuk kedua portofolio tersebut adalah sebagai berikut :

$$
\begin{aligned}
& \mathrm{T}_{\mathrm{p}}(\mathrm{LQ} 45)=\frac{0,3247-0,0510}{1,0993}=0,2490 \\
& \mathrm{~T}_{\mathrm{p}}\left(\text { Kompas 100) }=\frac{0,7794-0,0510}{1,3842}=0,5262\right.
\end{aligned}
$$

3. Indeks Jensen

Indeks merupakan selisih rata-rata return portofolio dengan nilai return menurut CAPM. Nilai positif menujukkan kinerja portofolio diatas rata-rata CAPM dan sebaliknya jika negatif sehingga yang diharapkan adalah portofolio memberikan nilai positif. Perhitungan indeks Jensen untuk kedua portofolio tersebut adalah sebagai berikut :

Jp $($ LQ45 $)=0,3247-\{0,0510+(-$ $0,0017-0,0510) 1,0993\}=0,3279$

Jp $($ Kompas 100) $=0,7794-\{0,0510+$ $(-0,0017-0,0510) 1,3842\}=0,8013$

\section{Pembahasan}

Berdasarkan hasil penelitian di atas dapat dilihat bahwa return dari portofolio yang dibentuk dari saham-saham pada indeks Kompas 100 menghasilkan return yang lebih tinggi daripada portofolio yang dibentuk dari saham-saham pada indeks LQ45. Return portofolio Kompas 100 sebesar 0,7794 sementara portofolio LQ45 hanya menghasilkan return sebesar 0,3247. Tetapi sejalan dengan prinsip high risk high return, tingkat risiko pada portofolio dari Kompas 100 juga lebih tinggi baik yang diukur hanya dengan risiko sistematik $(\beta)$ maupun dalam ukuran risiko total dengan pengukuran $\sigma p^{2}$. $\beta$ untuk Kompas 100 adalah 1,3842 sementara untuk LQ45 hanya sebesar 1,0993. Dari hasil di atas terlihat $\sigma p^{2}$ untuk Kompas 100 sebesar 0,0038 sementara untuk LQ45 hanya 0,0029.

Berdasarkan data di atas maka dapat dilihat bahwa tingkat return portofolio yang tinggi diikuti juga dengan tingkat risiko yang tinggi. Oleh sebab itu untuk dapat menilai portofolio manakah yang lebih baik perlu dilakukan penilaian kinerja portofolio tersebut. Bila dilihat dari hasil pengukuran kinerja baik menggunakan Indeks Sharpe, Treynor maupun Jensen maka kinerja portofolio yang dibentuk dari saham-saham pada indeks Kompas 100 memperlihatkan kinerja yang lebih baik dibandingkan dengan portofolio yang dibentuk dari saham-saham pada indeks LQ45. Hal ini dapat dilihat dari Indeks Sharpe Kompas 100 adalah $11,8247>5,0779$ yang merupakan nilai indeks Sharpe LQ45 dan indeks Treynor Kompas 100 adalah 0,5262 $>0,2490$ yang merupakan Indeks Treynor LQ 45. Hal ini menunjukkan bahwa kinerja portofolio Kompas 100 lebih baik dari LQ 45 baik melihat risiko sebagai risiko sistematik saja ataupun risiko total. Sementara nilai indeks Jensen Kompas 100 adalah $0,8013>0,3279$ yang merupakan nilai indeks Jensen LQ 45. Hal ini menunjukkan bahwa portofolio Kompas 100 memberikan selisih return diatas CAPM lebih besar dibandingkan dengan 
LQ45. Walaupun demikian, sebenarnya kedua portofolio tersebut mempunyai kinerja yang baik karena nilai indeks Sharpe, Treynornya cukup tinggi dan Indeks Jensennya juga sama-sama bernilai positif.

\section{Simpulan dan Saran}

\section{Simpulan}

Berdasarkan pengolahan data dan pembahasan yang telah dilakukan maka peneliti mengambil kesimpulan sebagai berikut:

1. Komposisi saham pada portofolio yang dibentuk dari Indeks LQ45 adalah PTBA sebesar 29,57\% ; ICBP sebesar $43,57 \%$; BBCA sebesar $25,06 \%$; PGAS sebesar $1,41 \%$ dan ANTM sebesar $0,9 \%$. Sementara untuk portofolio yang dibentuk dari indeks Kompas 100 berisikan 4 saham yaitu KREN sebesar 18,01\% ; CPIN 69,52\% ; PTBA sebesar 7,32\% dan JFPA sebesar $5,15 \%$.

2. Return atau imbal hasil yang diperoleh dari portofolio indeks LQ45 sebesar $32,47 \%$ dengan $\beta$ sebesar 1,0993 dan $\sigma \mathrm{p}^{2}$ sebesar 0,0029 sementara return portofolio yang dibentuk dari Indeks Kompas 100 sebesar 77,94\% dengan $\beta$ 1,3842 dan $\sigma p^{2}$ sebesar 0,0038 .

3. Jika dibandingkan kinerja kedua portofolio maka hasil analisis menunjukkan bahwa kinerja portofolio yang berasal dari Kompas 100 lebih baik daripada portofolio yang berasal dari Indeks LQ45 baik dengan menggunakan metode Indeks Sharpe, Indeks Treynor maupun Indeks Jensen.

\section{Saran}

Bagi investor yang ingin berinvestasi dalam instrumen saham sebaiknya melakukan diversifikasi dengan membentuk portofolio agar bisa mendapatkan portofolio yang optimal.

\section{Daftar Pustaka}

Almunfarijah. (2017). “Analisis Portofolio Optimal Saham Indeks LQ-45 dengan Model Indeks Tunggal di Bursa Efek Indonesia”, Jurnal Perilaku dan Strategi Bisnis, Vol.5, No.2, pp.168- 190.

Bangun, Deddy H. Anantadjaya, Samuel P.D. Lahindah, Laura. (2012). "Portofolio Optimal Menurut Markowitz Model dan Single Index Model : Studi Kasus pada Indeks LQ45", Journal of Management Studies, Vol 1, No 1, pp.1-24.

Buku Panduan Indeks Harga Saham Bursa Efek Indonesia. (2010). Jakarta : Indonesia Stock Exchange.

Hartono, Jogiyanto. (2012). Teori Portofolio dan Analisis Investasi. Edisi Ketujuh. Yogyakarta : BPFEYogyakarta.

Husnan, Suad. (2009). Dasar-dasar Teori Portofolio Analisis Sekuritas. Edisi Keempat. Yogyakarta : Unit Penerbit dan Percetakan Sekolah Tinggi Ilmu Manajemen YKPN.

Mahadwartha, Putu Anom. Gunawan, Pranata Yandi. (2012). "Pembentukan dan Pengujian Portfolio Saham-saham Optimal : Pendekatan Single Index Model”, Ekuitas : Jurnal Ekonomi dan Keuangan, Vol 20, No 4, pp.491510.

Oktaviani, Berlian Nanda. Wijayanto, Andhi. (2015). "Aplikasi Single Index Model Dalam Pembentukan Portofolio Optimal Saham LQ45 dan Jakarta Islamic Index”, Management Analysist Journal 4 (1), pp.189-202, http://maj.unnes.ac.id

Setiawan, Sandy. (2017). "Analisis Portofolio Optimal Saham-saham LQ45 Menggunakan Single Index Model di Bursa Efek Indonesia Periode 2013-2016", Journal of 
Accounting and Business Studies, Vol 1, No. 2, pp.1-19.

Sugiyono. (2010). Metode Penelitian Kuantitatif, Kualitatif dan R\&D. Cetakan ke 10. Bandung : Alfabeta.

Suliyanto. (2009). Metode Riset Bisnis. Yogyakarta : CV Andi Offset.

Tandelilin, Eduardus. (2010). Portofolio dan Investasi Teori dan Aplikasi. Cetakan Kelima. Yogyakarta : Kanisisus (Anggota IKAPI).

Wibowo, Windy Martya. Rahayu, Sri Mangesti. N.P, Maria Goretti Wi Endang. (2014). "Penerapan Model Indeks Tunggal Untuk Menerapkan Portofolio Optimal (Studi pada Saham-saham LQ 45 yang Listing di Bursa Efek Indonesia (BEI) tahun 2010-2012”, Jurnal Administrasi Bisnis, Vol 9, No 1, pp.1-9. http://administrasibisnis.studentjourn al.ub.ac.id

Witiastuti, Rini Setyo. (2012). "Analisis Kinerja Portofolio : Pengujian Single Index Model dan Naive Diversification", Jurnal Dinamika Manajemen, Vol 3, No 2, pp.122132.

http://journal.unnes.ac.id/nju/index.p $\mathrm{hp} / \mathrm{jdm}$

www.idx.co.id

Zahra, Fithriya. (2017). "Analisis Pembentukan Portofolio Saham Menggunakan Model Indeks Tunggal Pada Saham Indeks LQ-45 Periode Januari 2013 Sampai Dengan Juli 2016 di Bursa Efek Indonesia", Jurnal Sekretaris \& Administrasi Bisnis, Volume I, Number I, pp.41-56, http://jurnal.asmtb.ac.id/index.php/js $\mathrm{a} b$

Zarman, Nasri. (2017). “ Kinerja Portofolio Saham pada Perusahaan Makanan, Properti dan Pertambangan di Bursa Efek Indonesia", Esensi : Jurnal Bisnis dan Manajemen, Vol 7, No

2 , pp.247-260.
http://journaLuinjkt.ac.id/index.php/

e sensi

Zubir, Zalmi. (2011). Manajemen Portofolio Penerapannya Dalam Investasi Saham. Jakarta : Salemba Empat. 